\title{
ANTIGONE/ANTÍGONA (1961), DIRIGIDA POR GIORGOS TZAVELLAS
}

\author{
Ricardo MATAS PITAS
}

La primera versión cinematográfica de la sofoclea Antígona (representada por primera vez en el año 441 a. de C.) fue realizada por el heleno Giorgos Tzavellas (1916-1976) -también conocido con las variantes de Yiorgos y Yorgos, para su nombre propio, y de Javellas, en lo tocante a su apellido-, quien, de esa manera, iniciaría, en la gran pantalla, lo que, a partir de la década de 1960, sería una línea creadora imparable que habría de afianzarse no solo en lo que se ha denominado Etapa Áurea del Cine Griego (las décadas de 1950 y 1960), sino, también, en diversas y numerosas producciones internacionales que abordarían, con una finalidad divulgativamente artística, las obras de la tríada fundamental de los poetas trágicos helenos: Esquilo (524/524 - c. 456/455 a. de C.), Sófocles (497/496 - 406/405 a. de C.) y Eurípides (480 - c. 406 a. de C.). Finalidad apoyada en el solidísimo prestigio literario y dramático de sus puntos de partida.

No obstante, hay que mencionar que, en 1958, el italiano Vittorio Cottafavi (1914-1998) preparó una Antígona, según Sófocles, para la televisión de su país, ya considerada como un medio expresivo completamente válido a la hora de ofrecer productos culturales de calidad -opinión compartida, entonces, por su compatriota Roberto Rossellini (1906-1977)-.

Cuando Yorgos Tzavellas se lo plantea a su vez, ya había demostrado una resuelta capacidad para llevarlo a cabo: hombre del cine que, desde 1944, había dirigido diez títulos y escrito sus respectivos guiones, más dos para cintas ajenas; mientras que, así mismo, elaboraba sus propias obras teatrales. Es decir, su aproximación fílmica a la Antígona, de Sófocles, se nutre tanto de una consolidada experiencia cinematográfica como de un aquilatado conocimiento de los resortes dramáticos, hechos ambos que le permiten verter la pieza sofoclea al lenguaje audiovisual del séptimo arte, sin traicionar la esencia de aquella, ni como obra literaria leída ni como espectáculo representado, lo cual es patente en su ritmo grave, pero fluido, gracias a un sabio y elegante uso de la cámara, a menudo, en un movimiento sutil que evita el riesgo de caer en lo que, para muchos estudiosos y críticos del cine, se considera un anatema creativo: el teatro filmado. Sin embargo, nosotros pensamos que tal pecado no existe, bien al contrario, que se trata de una más de esas falacias argüidas por los aquejados de un excesivo prurito discriminador, durante décadas y décadas, para vituperar lo teatral a costa de enaltecer lo cinematográfico, aunque, paradójicamente, constriñendo su enorme potencial captador de la Realidad, ya que el cine, mal que les pese, sí puede absorber de múltiples maneras lo filmado. También, en el caso de trasladar a la pantalla una pieza dramática (otro tanto ocurriría con el medio televisivo). De aquí que no 
entendamos esa necesidad simplificadora que les endosa a las películas una forzada y forzosa adscripción a una categoría naturalista o imaginativa o lo que fuere (véase semejante afán taxonomista, por ejemplo, en el estudio monográfico Greek Tragedy into Film, de Kenneth MacKinnon, que, por otra parte, no deja de ser muy valioso en abundantes aspectos.

Así pues, Giorgos Tzavellas, con el respeto a la idiosincrasia del texto sofocleo y garantizando su acomodación a la imagen fílmica, nos facilita una versión que concentra la estilización inherente al Teatro de la Antigüedad Grecolatina, mas sin el temor de la servidumbre impersonal hacia los clásicos.

Esta Antígona recrea la historia del, sin lugar a dudas, personaje femenino más importante del drama heleno (corroborado mediante el grandísimo e irrefrenable número de adaptaciones cinematográficas y televisivas a él dedicado, muy por encima del que gira en torno a Medea, Electra, Hécuba, Fedra, Casandra, Ifigenia, Clitemnestra, Helena...). La fidelidad al verso y a la concepción temática de Sófocles trata las disyuntivas a las cuales ha de enfrentarse Antígona, cuya etimología onomástica significa 'la que está en contra de la familia', en un claro ejemplo de la caracterización folklórica que los nombres implican en los personajes que los portan -recuérdese cómo habría de ser una técnica muy empleada, siempre, en la cuentística tradicional e imitada por infinidad de escritores, por ejemplo, nuestro Benito Pérez Galdós (1843-1920)-. Personaje sobre el que pivota la acción medular de la obra, a causa de las diversas relaciones que establece con los distintos personajes (su hermana Ismene, su tío Creonte -ahora, rey de Tebas-, su novio Hemón -primo suyo e hijo de Creonte-, su tía Eurídice, toda la población tebana -un personaje colectivo representado por el coro de los ancianos-, incluso, consigo misma (lo que la conduce, en parte, a cometer el suicidio).

La elección de Antígona ante el dilema que se le plantea (respetar la razón natural frente a la razón política y todo lo que esta lleve aparejado) se alza como uno de los combates éticos más importantes de la Literatura Universal: si Aristóteles (384 a. de C. - 322 a. de C.), en su Poética (335 a 323 a. de C.), analizaba el sofocleo Edipo Rey (escrita hacia el 430 a. de C. y representada por primera vez alrededor del año 429 a. de C.) como el arquetipo perfecto de la tragedia helena, se podría aseverar que en la Antígona, de Sófocles, se iría mucho más allá de esa mostración inexorable del fatum de su padre, Edipo, para simbolizar lo que supone una toma consciente de postura en circunstancias terriblemente adversas. De ahí la riqueza de la actitud antigoniana en directa oposición al poder: el fin, cualquiera que fuere, no justifica los medios, dejando, en última instancia, a los poderosos en un callejón sin salida, abocados a su soledad amoral o inmoral y, por ello, a la autodestrucción.

En la película de Yorgos Tzavellas, se ve perfectamente este proceso en la Tebas eubea que le tocó vivir a una Antígona que se atrevió a salir del gineceo y cerrar con ella, en una suerte de in destino veritas, el truculento ciclo tebano, nacido de la maldición que aquejara a toda la familia por el crimen de Layo (constituido por tres grandes poemas: la Edipodia, la Tebaida y los Epígonos, pertenecientes a la Época Arcaica de Grecia -se datan entre los siglos VIII y VII a. de C.-).

Pudo Tzavellas conseguir un logro óptimo porque se arropó con un excelente reparto que debe ser mencionado: Irene Papas (1926) / Antígona, Marcos Katrakis (1908-1984) / Creonte, Maro Kodou (1934) / Ismene, Nikos Kazis (1927-2006) / Hemón, Ilia Livykou (19192002) / Eurídice, Tzavalas Karousos (1904-1969) / Tiresias, Giannis Arghyris (1918-1993) / Centinela, Byron Pallis (1923-1995) / Mensajero, Thodoros Moridis (1905-2003) / Corifeo del Coro de Ancianos de Tebas. 


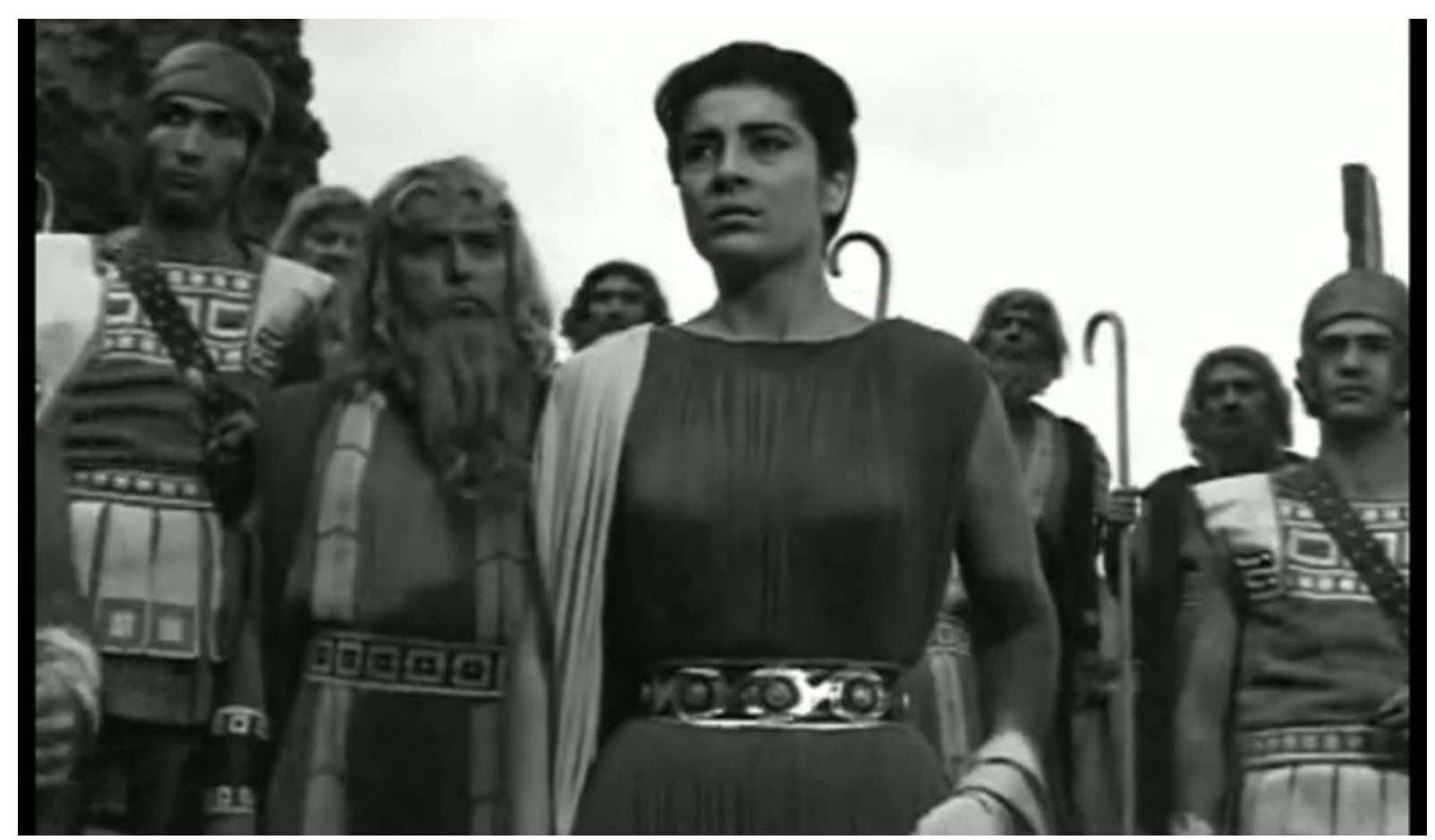

Antigora. Giorgios Tzavellas

Y, por supuesto, esta producción de Demetrios Paris (1921-1982) contó con un plantel magnífico para la fotografía (Dinos Katsouridis [1927-2011]), la dirección de la segunda unidad (Vasilis Antonakos), los decorados, la dirección artística y el vestuario (Giorgos Anemogiannis), el diseño de producción (Hans Hurch), el montaje (Giorgos Tsaoulis) y la música (Argyris Kounadis [1924-2011]).

Orgullosos del resultado de su trabajo, Antígona fue llevada al undécimo Festival Internacional de Cine de Berlín para participar en el apartado de competición, en un momento en que Grecia, tras la Guerra Civil de 1944-1949 (la primera gran confrontación de la Guerra Fría 1947-1991), alcanzaba el desarrollo postbélico y la integración en el Bloque Occidental (1949-1967), antes de la Dictadura Militar que la sojuzgaría entre 1967 y 1974, reavivando los ecos políticosociales que se oyeron en tiempos de la legendaria Antígona. 